\title{
Research on the Construction of Library Smart Service System for the Aged
}

\author{
Xiaomin $\mathrm{Hu}^{*}$, Xiyan Lv \\ School of Economics and Management, Beijing Jiaotong University, Beijing 100044, China \\ *Corresponding author. Email: 15800986137@163.com
}

\begin{abstract}
In the face of the coming of an aging society, libraries must think about how to improve their ability to provide smart service for elderly users. This article explains the connotation of smart service, with emphasis on the sharing of library resources, and analyses the current status of smart service for elderly users based on the characteristics of the elderly. With elderly users as the center and user data as the basis, a comprehensive service system consisting of resources, equipment, librarians, and environment is constructed. At last, strategic suggestions are provided to improve the library's smart service ability.
\end{abstract}

Keywords: Smart library, service system, elderly users

\section{INTRODUCTION}

The rapid rise of artificial intelligence and big data technology has given a powerful driving force to the innovation and transformation of human life. Libraries are constantly transforming to meet the increasing demands of technology and services.

For the elderly, the emergence of smart libraries is both a gospel and a challenge. On the one hand, diversified service channels have built bridges for the elderly with limited physical conditions to connect with the world. Smart service are not limited by time and space. People can get the resources they need anytime, anywhere. On the other hand, the elderly are generally weak in accepting and understanding new things. The change in reading style makes the elderly unable to adapt for a while. A variety of advanced equipment makes the elderly confused. In addition, the lack of information literacy and operational knowledge makes the elderly unable to make full use of smart libraries. Under the social background of universal reading and lifelong learning, how to use high-tech and smart service methods to improve the reading experience of the elderly is a problem that libraries must pay attention to. So it is also particularly important to build a library smart service system suitable for elderly readers.

\section{ANALYSIS OF SMART SERVICE}

\subsection{Connotation of Smart Service}

In 2008, the concept of "smart earth" emerged, and the concept of "smart" began to be applied and developed in various fields, such as smart cities, smart transportation and smart campuses. As an important support for the realization of smart cities, smart libraries have gradually attracted the attention of relevant scholars. The research and practice on smart libraries have been carried out one after another. The main purpose of the smart library is to provide a good learning environment and services for users based on their information needs and personalized characteristics [1]. Smart service adapted to smart libraries emerges as the times require. With the deepening of research, the content of library smart service is becoming more and more abundant.

The library is rich in graphic information and digital resources, which is an important channel for the public to obtain knowledge. The realization of smart services will help libraries to better play the social function of cultural communication. As a shared resource of the society, the library's smart service is oriented to the whole society and all human beings. People of different ages, genders and backgrounds can equally enjoy all the services of the library. In the process of building a smart library, the spiritual and cultural needs of the elderly should not be ignored. Libraries have the responsibility and obligation to provide smart services suitable for older readers according to the characteristics of the elderly, so that the elderly can have a sense of trust, security and happiness in the emerging smart library.

\subsection{Characteristics of Elderly Users}

First, many old people have difficulty in walking and move slowly. Some even need crutches or wheelchairs to go out. These people will pay attention to whether the library is safe and convenient. Second, older people's audio-visual ability becomes worse, and they have special needs for font size and volume. Third, the lack of Internet knowledge and the unfamiliarity of new technology and new equipment among the elderly create obstacles to the acquisition of network information. Fourth, the elderly and the younger generation have different life experiences and backgrounds, their interests and hobbies are also different. 


\subsection{Status Quo of Serving Elderly Users}

\subsubsection{Low attention to elderly users}

At present, the service objects of smart libraries are mainly young people, and the attention to older users is relatively low. In order to speed up the construction of smart libraries, the elderly as a vulnerable group are often overlooked or even excluded from the scope of planned services. Many community libraries only provide traditional reading services for the elderly, and think that the elderly are not suitable for digital reading and mobile reading [2].

\subsubsection{Digital resources for the elderly are} scarce

The needs and preferences of the elderly and young groups are obviously different. Digital resources that are suitable for the young may not be suitable for the old. However, when the library builds digital resources, it rarely pays attention to the needs of elderly users. Due to the lack of digital resources for the elderly, the distance between the elderly and the smart library is gradually widened.

\subsubsection{Lack of coaching and training}

The emergence of smart libraries puts forward higher requirements for the professional knowledge and information literacy of the elderly. The elderly have a weak ability to learn new things, and have difficulties in finding digital resources and using equipment. The library's support for elderly users is weak, and the guidance and training needs to be further improved.

\subsubsection{Lack of equipment suitable for the elderly}

With the increase of age, the elderly's eyesight, hearing, physical strength, etc. have declined to a certain extent, and general facilities and equipment cannot meet the special needs of elderly users. At present, public libraries provide younger users and ordinary users with more complete facilities and equipment, but they ignore the experience of older users and lack facilities and equipment that match the elderly.

\section{CONSTRUCTION OF LIBRARY SMART SERVICE SYSTEM FOR THE ELDERLY}

It is of great significance to the development of libraries to construct a library smart service system according to the characteristics and perspective of elderly users. It helps elderly users to enter the library's smart era without barriers, so that the value of "smart" can be fully demonstrated. The needs of elderly users are the starting point of all services, and meeting the needs of users is the ultimate goal of smart services. With elderly users as the center and user data as the foundation, a comprehensive service system consisting of resources, equipment, librarians, and environment is constructed to help elderly users truly feel the great potential of smart libraries. The overall idea is illustrated in Figure 1.

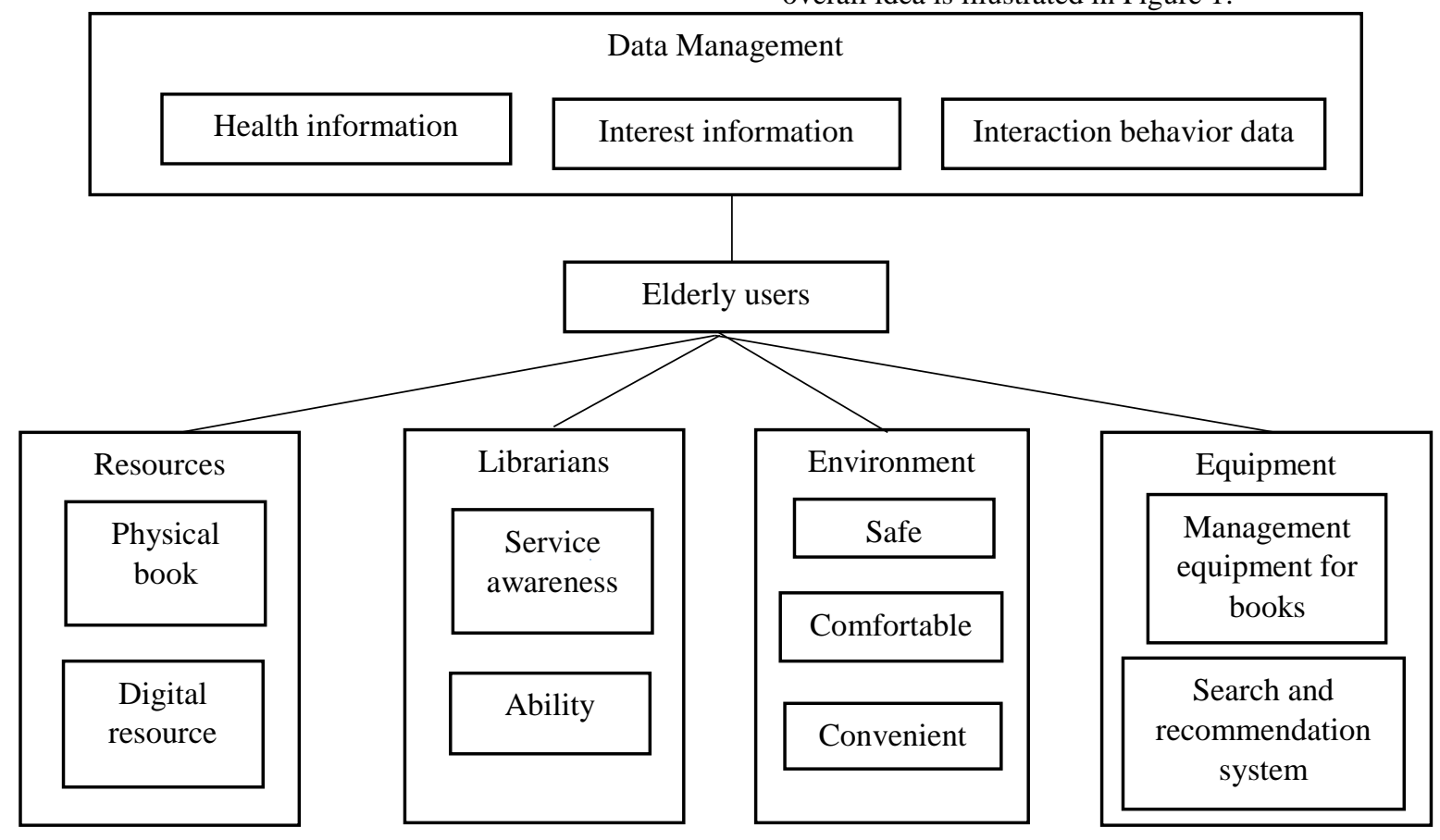

Figure 1 Library smart service system for the elderly 


\subsection{Data Management}

With the advent of the era of big data, the library is no longer just a place to collect paper materials, but also a place to gather massive amounts of data. The data contains information such as the user's intentions, interests, habits, etc. Mining and analysis of these data can strengthen the humanistic care and promote pertinence and individuation of the library services [3].

In the library's smart service system, the data of elderly users can be divided into health information, interest information, and interaction behavior data. Health information includes information such as eyesight, hearing, mobility, and acute illness of elderly users. By analyzing this information, on the one hand, it can provide reference for the design of a network-friendly interface for the elderly, and on the other hand, it can provide users with the best route, the best reading location, emergency rescue and other personalized services. Interest information can be displayed by users' retrieval records, page browsing records, download records, borrowing data, etc. These data can reflect users' demand and change trend, providing a basis for the scheduling and adjustment of the resources of elderly users. Interactive behavior data refers to the total contact time, interface residence time, function usage frequency, usage habits and other information during the use of digital devices by elderly users. This kind of data reflects the digital literacy level of the elderly users, is the assessment of the availability and friendliness of equipment, and is an important basis for the design of training courses and the personalized construction of equipment.

\subsection{Resources Construction}

In the collection construction of smart library, the library should pay attention to the cultural needs of the elderly group and build a resource zone based on the preferences and characteristics of the elderly. Libraries also need to fully understand the needs of elderly users for different types of resources, set a reasonable resource structure, and increase the enthusiasm of the elderly to use various resources. On the one hand, library need enrich traditional physical book resources, such as magazines, newspapers and books; On the other hand, in order to build digital resources suitable for the elderly, besides direct purchase, new technologies can be used to screen and integrate network resources to the greatest extent to expand the number of digital resources. As resources continue to expand, library resources will inevitably develop to the cloud. Cloud storage mode realizes the scientific integration of resources and eases the pressure of data storage.

The development level of each library is unbalanced, which makes the library's resource construction capacity also have differences. Cooperation and sharing between libraries can greatly improve the utilization of collection resources, reduce operating costs, facilitate the construction of smart libraries, and promote the realization of smart services.

\subsection{Librarian Construction}

The smart librarian is an irreplaceable role in the library's elderly service system. Librarians, as the key link between libraries and users, are an important channel to understand the characteristics, needs and suggestions of elderly users. For elderly users, librarians should establish the consciousness of active service, actively find out the difficulties and needs of users, and be good companions and supporters of elderly users. The analysis of elderly users' data and the collection of feedback information are also important tasks for librarians. In addition, librarians need to improve their ability of interview and investigation, technology application, reading and promotion, data analysis and rapid learning. Libraries can regularly conduct experience-sharing sessions to provide librarians with a platform for exchange and learning, and speed up the construction of smart service ability.

\subsection{Space Construction}

The physical space helps to enhance the communication between the personnel in the library, promote the collision of thinking, and facilitate the spread of knowledge [4]. Considering the physical condition of the elderly, libraries should first ensure the smooth operation of barrier-free facilities. 3D navigation service system can provide convenience for elderly users to get resources that they need. Tables, chairs, bookshelves, toilets, etc. should be designed according to the physiological characteristics of the elderly. Appropriate lighting, pleasant temperature and quiet atmosphere help users learn and think more efficiently. The intelligent lighting system and intelligent temperature control system can sense and adjust the brightness and temperature in real time, create a harmonious and comfortable environment, and provide a good environmental foundation for smart services.

\subsection{Equipment Construction}

The smart device is an indispensable part of the smart service of the library. First, use RFID tags, self-service borrowing and returning machines, self-service sorting equipment, book inventory equipment, smart bookshelves, etc. to achieve accurate and efficient management of books [5]. Second, build a smart search and smart recommendation system suitable for elderly users. In response to the operating habits of the elderly, various search methods such as voice input and handwriting input are added to make it easier for the elderly to obtain resources. The retrieval results are presented in various ways such as video, voice, pictures, large fonts, etc., to 
provide intuitive and clear results display for the elderly users. Third, the retrieval system is associated with the recommendation system. The knowledge map, data mining and other technologies are used to predict user needs, so as to make automatic recommendation in the process of user retrieval.

\section{STRATEGIES}

\subsection{Establish Service Awareness}

User satisfaction is the "soul" of the smart library, and service awareness has a decisive impact on service quality. For elderly users, smart librarians need to maintain an active, open and inclusive attitude, pay attention to the special needs and difficulties of elderly users, do not exclude, give up, or complain, and ensure the quality of services for elderly users. During the recruitment, training, and evaluation of librarians, library must not only emphasize business literacy and professional knowledge, but also pay attention to service attitude and service awareness. On the one hand, the elderly group should be regarded as ordinary users of smart libraries, so that serving elderly users becomes a normalized work; on the other hand, the elderly group should be regarded as a special group, which should be paid attention and care. Good service awareness is of great significance to achieve smart service.

\subsection{Emphasize User Training}

The library can regularly hold lectures on related skills and recruit highly qualified volunteers to give one-on-one guidance to the elderly. In addition to offline training, online courses can be launched with advanced technology and online platforms, so as to achieve an organic combination of offline guidance and online autonomous learning. Older users can have more learning opportunities and a more relaxed learning environment. The "offline + online" user training model provides a variety of learning channels for elderly users and promotes the innovation and development of the training system for elderly users.

\subsection{Improve Resource Quality}

Whether the resources are of high quality and attractive is directly related to the satisfaction of older users. In resource construction and resource display, more consideration should be given to users' reading characteristics and interests, and the resource structure should be optimized to meet the needs of elderly users. At the same time, libraries should increase the number of audio books and big-character books for the convenience of elderly users.

\subsection{Develop Web Services for the Elderly}

As the new development direction of society, the interconnection of all things will promote a fundamental change in people's lifestyle. Keeping up with the pace of the times is the desire of every elderly person. A suitable network interface can lower the threshold for the elderly to obtain network knowledge. The smart library should develop websites, applications, and official accounts for the elderly to expand access to information. In order to improve the enthusiasm of the elderly, the page should be simple and friendly, the directory should be clear and easy to understand, and the operation steps should be few.

\section{CONCLUSION}

The library serves the whole people. In the "smart era", the elderly have a weak ability to obtain information, and they deserve more attention from the smart library. It is the responsibility of the library to do well the information service for the elderly users and establish a perfect service system, which is also the development needs of the times. The smart service system constructed in this paper provides a reference for library development.

\section{REFERENCES}

[1] Ruan, Jian, and Shengbin Wang, Study on innovation of smart library service model in the era of big data, in: international conference on electrical and electronics engineering, Jinan, China, 2016, pp. 450-453. DOI: https://doi.org/10.2991/iceeecs-16.2016.207.

[2] Liu Juanping, Yang Yurong, A study on digital reading of old readers in community, Library, (2) (2015) 104-106.

[3] Burgess, John T F, Smart-world technologies and the value of librarianship, Computers in Libraries, 30(10) (2010) 12-16.

[4] XIA Lixin, BAI Yang, ZHANG Xinyi, Integration and reconstruction: a new development pattern of smart library, Journal of Library Science in China, 44(1) (2018) 35-49.

[5] Wang Yingchun, He Xinqian, Liu Yanquan, Development path research on library smart service mode, Library Work and Study, (1) (2018) 12-17. 